\title{
Assessment of Young Children on Entry to School: Informative, Formative or Performative?
}

\author{
Sigrid Brogaard Clausen ${ }^{1}$, Sofia Guimaraes ${ }^{2}$, Sally Howe ${ }^{3}$, Michelle Cottle \\ Early Childhood Research Centre ${ }^{1,2,3,4}$ \\ University of Roehampton, London, $U K^{1,2,3,4}$
}

\begin{abstract}
This article examines the recent move towards baseline assessment in early childhood education in England. From 2016, the government will introduce the use of assessment on children's entry to school (age 4-5). In this light it is significant to establish how the move towards a baseline assessment that sits within the current early years and school entry context within England. The government intend this baseline assessment to be a part of monitoring accountability and school effectiveness. Existing baseline assessment is predominantly task-oriented and adult-led and there are well-documented issues regarding the validity and reliability of this kind of data for accountability purposes. Therefore evidence building on previous assessment research will be investigated leading into a discussion on how an observation-led baseline assessment which prioritises children's well-being and characteristics of effective learning might contribute to positive early experiences of school. On this basis the article will conclude with outlining ongoing research on a piloted observation-led baseline assessment in 12 schools in South East England
\end{abstract}

\section{Introduction}

Since the late 1990s the use of assessment on entry to school has widened internationally, with a number of countries using on entry assessment to give 'performance indicators' of children's attainment when they come into school [45].

Assessing children's achievement and progress is an important part of Early Years teachers' roles. However, identifying children's development and learning needs can take different forms and serve different purposes $[5,14]$. These assessments may be used by teachers to inform future planning, as means of improving attainment [33], and as a baseline from which to measure future progress [22].

In 2014, the UK Government announced that schools in England will be expected to assess children within the first six weeks of starting school in order to provide an indication of their attainment on school entry (baseline assessment). The results from this assessment will be measured against end of primary education test results as a means of determining school effectiveness, both as a predictor of children's later attainment and as a way of allocating funding.

In England observations have been a key part of the assessment process in early years education. The process of assessing learning is widely debated, due to the complexity of using assessment 'for', 'as' and 'of' learning [5]. Key factors in the dynamic between wellbeing and learning are also being increasingly recognized as important for children's successful learning.

This article presents a theoretical framework suggesting that an assessment on entry to school, based on observation and taking into account involvement and wellbeing, will provide teachers with meaningful information about children's learning, and be a more robust indicator of later attainment. To provide a context for this framework, this article first discusses previous policies and research evidence which indicates a clear need for urgent research in order to understand and inform the implications of this new policy. The article ends by outlining research currently underway that investigates teachers and head teachers' perspectives involved in a pilot of a baseline assessment which prioritises children's well-being and characteristics of effective learning.

\section{The Development of Baseline Assessment for accountability purposes in England}

The proposed use of baseline assessment to judge school effectiveness is not a new phenomenon. In 1998 the New Labour government developed a policy requiring schools to use accredited baseline schemes, which would then be assessed against the children's performance on later nationally agreed tests in order to provide 'value added data' on school's performance [23]. 'Value added' was the term used by the Government to define progress that could be attributed to the effectiveness of the school in promoting children's attainment in language and literacy, mathematics and social skills. The majority 
of these baseline assessments were adult-led and task oriented [23]. In 2002, as part of the introduction of the Foundation Stage (children aged 3-5), baseline assessment was replaced by the Foundation Stage Profile to be completed for each child by the end of his or her time in the foundation stage, which (typically) is the end of the reception year [11]. This was partially to do with the nature of the school starting age in England, where compulsory schooling begins from the term after a child's fifth birthday, but children generally begin school in what are known as reception classes in the year that they turn five, some only a few weeks after their fourth birthday. The Foundation Stage profile was intended to provide a summative account of children's attainment at the end of the reception year.

The present move towards introducing baseline assessment for children at the start of reception is in part, a response to schools' concerns that they were not being given credit for the considerable learning that takes place during the reception year [10]. The response to this concern forms part of the assumption that accountability is key to "raise standards" and levels of achievement at both classroom and school level. The attempt to measure children's progress in Primary school based on a single entry score which is then evaluated against end of primary school results, places greater emphasis on schools providing performative data and issues of "school effectiveness". Education policies throughout the last two decades have largely focused on economic aims, involving the increased use of market approaches that emphasise diversity, competition and choice with a concurrent and often conflicting emphasis on standards and achievement [21]. These include prescriptive curriculum initiatives, a national system of standardized testing, school league tables, and external scrutiny. As a result, the belief that testing is linked to effectiveness and quality has been internalized in primary schools $[21,26]$. There are, however, some distinct difficulties in using data from baseline assessments in this way.

\subsection{Questioning the validity of test based assessment focused on academic skills/knowledge as predictors for achievement and attainment}

The use of baseline assessment in 1998 faced considerable criticism in relation to its validity and reliability as a measure of value added or 'adjustment comparison' [15, p385]. Issues of reliability concern the uncertainty of 'value added' estimates to provide anything other than very limited comparisons between schools. In addition, much of the variation between schools was linked to factors such as gender, socio-economic status and ethnicity over which schools have limited, if any, control [15,
37, 38]. A further issue is the lack of correlation between what is measured at the beginning (baseline assessment scores) and what is measured in national tests at the end of primary school. The added complication of multiple baseline tests compromised effective national comparisons. Moreover, using a baseline test at the beginning of Reception does not take into account the effects of prior to school experience, which may have a considerable effect on school attainment or the fact that many schools have a high turnover of children moving from one school to another [15, 32, 41].

There are three distinct threats to validity. Firstly, when children first go to school they are learning a great deal about the way in which school works and the rules of behaviour that are expected of them. It is quite common for children to experience 'dips' in performance/attainment during transition phases [36] and many children may not show their true abilities for some time. Schools who assess children at weeks 1 or 2 may have the closest to a true baseline, but may underestimate the performance of children who take time to settle, whereas by week 6 children will not only have settled, but may have, for example, learned new literacy or mathematics skills/knowledge, and so record higher scores (23, p157). Secondly, teachers may be encouraged to underestimate the attainment of children at four and five years old [15], in order to show greater 'school effectiveness'. The third threat to validity is the use of current levels of attainment and performance in order to predict later attainment which, according to [25], has little scientific justification. Baseline data concerning children's performance may reflect some aspects of children's learning experience, but does not indicate their capacity to learn [.42]

Baseline assessment results, whether for the purpose of identifying children's learning needs or to be used for value-added purposes need to be very carefully interpreted [24] as they ignore the fact that non-school factors continually influence children as they progress through school [18]. The above arguments mean that any statistical comparisons both within and between schools need to be treated with a great deal of caution [15].

Therefore in order to be effective, new baseline assessment instruments need to be carefully designed to take into account the limitations highlighted here.

\section{Developing baseline assessment in the light of current policy and research}

The government criteria for the new baseline assessments make it clear that they must produce a single, numerical score, based on binary decisions about children's performance on a range of indicators. The majority of these should link clearly 
with the expected outcomes for language, literacy and numeracy in the EYFS Guidance [9]. A single score, however, will not easily offer teachers information about how to develop their teaching, omitting one of the key purposes of on entry to school assessment. As Nutbrown argues, it is very important for teachers to "know what children can do, not simply that they do not achieve a specific task" [32, p41 original italics]. More importantly, assessments should offer relevant information about children's holistic learning and development and not simply focus on a reductionist view on numeracy and literacy data [35]. There are other factors, relating to children's feelings of well-being and characteristics of effective learning [43], that may prove to be more effective predictors of children's school progress than their performance in narrow linguistic and numeric tasks.

\subsection{Wellbeing and characteristics of effective learning as important indicators of children's attainment.}

A significant body of research has systematically highlighted the importance of children's early socialemotional skills in their later development and academic outcomes. Children with better emotional wellbeing make more progress in primary school [16] as social-emotional skills are crucial to their academic achievement and development [31]. Several social-emotional competencies have been identified as important for successful adjustment to primary school, achievement and positive outcomes. These include the development of emotional understanding and regulation, the ability to cope with stress, the development of autonomy and trust, the development of empathy and the formation of positive relationships with others [19].

As children further develop their ability to engage in the new learning context and interact with others they will continue to develop their sense of self. Research indicates that children with more positive self-beliefs about their academic abilities tend to have higher levels of academic achievement in primary school [31]. Children who enjoy school are more likely to be motivated and engaged in learning, which will affect their school work at a later point in time [16].

More formal learning environments place additional demands on children's ability to pay attention, remember instructions and demonstrate self-control. This kind of self-regulation is fundamental to how children interact with others and the environment consequently affecting their learning [30]. Self-regulation is a comprehensive and multidimensional construct that includes both cognitive and emotional regulation. It includes aspects of attentional or cognitive flexibility, working memory, inhibitory control and the ability to regulate emotions as it requires being able to voluntary focus and sustain attention while ignoring distractions [27, 28]. The development of these skills before formal schooling seem to be one of the strongest predictors of their learning and later academic achievement. Early self-regulation has been systematically associated with children's later academic achievement in mathematics and literacy [27, 30].

\subsection{The need for baseline assessment to be grounded in observation of children's self-initiated activity}

Using observation to assess children's learning is a key principle within early years pedagogy and assessment [12, 35], one that has been carried through from the work of early childhood pioneers such as Frederick Froebel and Susan Isaacs to the present day. It has been and continues to be prominent in the early years curriculum in this country [9] and has been used as a privileged method of assessment in early years education across most European countries [14]. This in also in line with the "observational assessments" integral to the Early Years Foundation Stage Profile [9] which is being replaced with the Baseline assessment. Observational assessment has been highlighted as integral to effective early years provision, with a recommendation that "assessment should be based primarily on the observation of daily activities that illustrate children's embedded learning." [43; 35].

It is also important to consider the type of activity that is being assessed and how that relates to children's achievement and performance. It has been established that assessment which focuses on children's self-initiated activities provides more reliable data of children's current levels of understanding. Young Children show higher signs of emotional well-being when they perceive a task as play [20] and demonstrate deeper levels of task engagement and use a wider range of strategies to solve challenges when they are engaged in selfinitiated play scenarios [29]. Therefore, observations of child-initiated learning are extremely valuable and can significantly contribute to the reliability of the information gathered about the child.

However, there has been much debate over the proportion of child- and adult-initiated learning that should be evidenced as part of early years assessment processes [e.g. 41]. A separate, adultinitiated series of 'tests' or tasks, which form the basis of many baseline assessments [23], whilst they may provide high statistical reliability is unlikely to be a reliable measure of children's learning, particularly when, as argued above, it is reduced to a score. In order to understand children's learning, 
practitioners need to explore the relationship between children's play, their developing emotional life and their understandings of their experiences [12].

\section{Repositioning assessment with a note of caution}

Kyriakides [22] argues that baseline assessments should have the potential to be used both as a basis for evaluating school effectiveness and as a tool for teachers to help children make progress in their learning. This raises the question of whether the baseline assessment process can offer teachers relevant formative and summative data in order to inform their teaching [18] and provide the performance indicators that are the aim of the government. This question needs to be understood in the light of the intensification of accountability that occurs within a model of assessment as providing information on school (and teacher) effectiveness, which may be attractive to policy-makers and perhaps parents as a guarantor of minimum standards within educational organisations [13]. However, accountability frequently reduces the value of both educational organisations and the individuals within them to performances that evidence productivity or to particular 'displays of quality' [4, p210]. The negative effects of high stakes testing regimes on children's motivation, self-esteem and learner identity are well-documented [17, 34]. This is equally the case with the effects of performanceoriented school cultures on teachers' levels of stress, their professional identities and inevitably their teaching strategies [44]. When the language of education is limited to a list of pre-standardised indicators, conceptions of learning and ability are narrowed [6] and the space for informal learning and provisional understandings shrinks, concealing the fact that learning is transient, dependent upon context and time and 'may manifest itself weeks, years, generations, after teaching...in forms that do not look like the original at all' [40, p318].

The baseline assessment initiative raises concerns about the 'top down' pressure that is increasingly influencing the experiences of children in their earliest years $[1,7]$ limiting opportunities for childinitiated learning and sustained shared thinking, and taking no account of the importance of motivation, self-regulation and feelings of well-being as prerequisites to full engagement in learning activities $[16,31]$. To understand the full implications of such policies, and to prevent teaching revolving around the production of auditable performances [13] where conceptions of learning and ability are narrowed [6], Apple [3, p232] proposes a framework of 'repositioning', examining how these policies are experienced from the standpoint of those who have less power.
There is, therefore an urgent need to conduct research with teachers who will be conducting baseline assessments and to understand how they sit within their current practices and values, and the feasibility of using the data gathered in the assessment to inform children's learning. This article forms part of an ongoing research project focusing on the perspectives of reception teachers and head teachers. These teachers, located in 12 schools in the South East of England, are working in collaboration with a training provider to pilot a new observational led baseline assessment that takes account of wellbeing and involvement as being important starting points for children's learning. The research will be located within a wider debate on Government policy and contemporary developments of early years and primary curricula.

\section{Conclusion}

The English government will be introducing baseline assessments in reception classrooms from 2016 in order to measure children's attainment in primary schools and to hold the schools to account. In so doing there is a need to learn from previous experiences of baseline assessments. In addition, and setting aside the key challenges of how to assess transient learning and how to develop numerical scores on the multifaceted and complex process of learning, we must acknowledge the growing research that points to the importance of children's socioemotional skills, particularly the aspects that have been identified to affect children's learning, development and wellbeing. These include their ability to cope with transition and the adjustment to primary school, the importance of empathy, trust and the formation of positive relationships with others and the development of their autonomy and selfregulation skills. The question remains whether an on entry to school assessment can include informative data for formative planning and satisfy government requirements with regard to accountability. The only way of getting to know whether this is feasible is to elicit the experiences of those involved in the process.

\section{References}

[1] Adams, S., E. Alexander, M. Drummond, \& J. Moyles (2004) Inside the Foundation Stage: Recreating the Reception Year.

Report commissioned and published by the Association of Teachers and Lecturers.

[2] Alexander, R., (2009) Children, their World, their Education: Final Report and Recommendations of the Cambridge Primary Review, London: Routledge. pp.586 
[3] Apple, M. W., (2006) Educating the 'Right' Way: Markets, Standards, God, and Inequality, 2nd ed. edition, London: Routledge.

[4] Ball, S., (2001) 'Performativities and Fabrications in the Education Economy: Towards the Performative Society' in Gleeson, D., et al (eds.) The Performing School: Managing, Teaching and Learning in a Performance Culture, London: RoutledgeFalmer, pp.210226

[5] Basford, J. \& Bath, C. (2014) Playing the Assessment Game: an English Early Childhood education Perspective. Early Years: An International Research Journal, 34:2, 119-132.

[6] Boaler, J., D. Wiliam \& M. Brown, (2000) 'Students' Experiences of Ability Grouping - Disaffection, Polarisation and the Construction of Failure'. British Educational Research Journal, 26 (5), 631- 648.

[7] Cottle, M. \& E. Alexander, (2012) 'Quality in Early Years Settings: Government, Research and Practitioners' Perspectives', British Educational Research Journal, 38 (4) pp.635-654.

[8] DfE (2014) Early Years Foundation Stage Profile Handbook. Standards and Testing Agency, DfE.

[9] DfE, (2014) Statutory Framework for the Early Years Foundation Stage, DFE-00337-2014, London: DfE.

[10] DfE (2014) Reforming Assessment and accountability for Primary Schools Government Response to Consultation on Primary School Assessment and Accountability, DFE00102-2014.

[11] Department for Education and Skills DfES/ Qualifications and Curriculum Authority (QCA) (2002) The Curriculum Guidance for the Foundation Stage Early Learning Goals, London: DfE/ QCA.

[12] Drummond, M. J., (2003) Assessing Children's Learning (2nd Edition), London: David Fulton Publishers. Primary curriculum series, pp.195.

[13] Elliot, J., (2001) 'Characteristics of Performative Cultures: Their Central Paradoxes and Limitations as Resources for Educational Reform' in Gleeson, D., et al (eds.) The Performing School : Managing, Teaching and Learning in a Performance Culture, London: RoutledgeFalmer, pp.192-209.

[14] European Commission/EACEA/Eurydice/Eurostat (2014). Key Data on Early Childhood Education and Care in Europe. 2014 Edition. Eurydice and Eurostat Report. Luxembourg: Publications Office of the European Union.

[15] Goldstein, H. \& D. Spiegelhalter, (1996), League tables and their limitations: statistical issues in comparisons of institutional performance

Journal of the Royal Statistical Society. Series A (Statistics in Society), 159, 3, 385-443.

[16] Gutman, L. \& J. Vorhaus, (2012) the Impact of Pupil Behaviour and Wellbeing on Educational Outcomes The Childhood Wellbeing Research Centre. DFE-RR253, London: Department for Education.
[17] Harlen, W. \& R. Deakin Crick, (2002) A Systematic Review of the Impact of Summative Assessment and Tests on Students' Motivation for Learning, London: EPPICentre, Social Science Research Unit, Institute of Education. pp.147.

[18] Harris, D. (2010) Clear Away the Smoke and Mirrors of Value-added. Phi Delta Kappan, 91, 8 66-69.

[19] Hotulainem, R. \& K. Lappalainem, (2011) 'PreSchool Socio-Emotional Behaviour and its Correlation to Self-Perceptions and Strengths of Young Adults.', Emotional and Behavioural Difficulties, 16 (4) pp.365381.

[20] Howard, J \& K. McInnes, (2012)

The impact of children's perception of an activity as play rather than not play on emotional well-being.

Child: Care Health and Development, 39, 5, 737-742.

[21] Jeffrey, B. \& G. Troman, (eds.) (2012) Performativity in UK Education: Ethnographic Cases of its Effects, Agency and Reconstructions. Gloucestershire: E\&E Publishing. pp292.

[22] Kyriakides, L., (2002) 'A Research-Based Model for the Development of Policy on Baseline Assessment', British Educational Research Journal, 28 (6) pp.805-826.

[23] Lindsay, G. \& A. Lewis, (2003) 'An Evaluation of the use of Accredited Baseline Assessment Schemes in England', British Educational Research Journal, 29 (2) pp.149-167.

[24] Lindsay, G. \& M. Desforges, (1999)

The use of the Infant Index/Baseline-PLUS as a baseline assessment measure of literacy

Journal of Research in Reading, 22, 1, 55-66.

[25] Lucas, B. and G. Claxton, (2010), New kinds of smart: how the science of learnable intelligence is changing education. Maidenhead, England: Open University Press.

[26] Mahony, P. \& I. Hextall, (2001) 'Performing and Conforming' in Gleeson, D. \& C. Husbands (eds.) The Performing School : Managing, Teaching and Learning in a Performance Culture, London: RoutledgeFalmer, pp.174-91

[27] McClelland, M. \& C. Cameron, (2011) 'SelfRegulation in Early Chidhood: Improving Conceptual Clarity and Developing Ecologically Valid Measures.', Child Development Perspectives, 6 (2) pp.136-142

[28] McClelland, M., A. C. Acock, A. Piccinin, S. A. Rhea \& M. C. Stallings, (2013) 'Relations between Preschool Attention Span-Persistence and Age 25 Educational Outcomes', Early Childhood Research Quarterly, 28 (2) pp.314-324

[29] McInnes, K., J. Howard, G. E. Miles \& K. Crowley, (2009) 'Behavioural Differences Exhibited by Children when Practising a Task Under Formal and Playful Conditions', Educational and Child Psychology, 26 (2) pp.31-39

[30] Montroy, J., R. Bowles, L. Skibbe \& T. Foster, (2014) 'Social Skills and Problem Behaviours as Mediators of the Relationship between Behavioural Self-Regulation and 
Academic Achievement.', Early Childhood Research Quarterly, 29 pp.298-309

[31] Niehaus, K. \& J. Adelson, (2013) 'Self-Concept and Native Language Background: A Study of Measurement Invariance and Cross-Group Comparisons in Third Grade', Journal of Educational Psychology, 105 (1) pp.226-240

[32] Nutbrown, C., (1999), 'Baseline assessment of writing: the need for reconsideration', Journal of Research in Reading 22(1) 37-44

[33]Ofsted (2011) The Impact of the 'Assessing Pupils' Progress’ Initiative. Ofsted/Ref: 100226.

[34] Reay, D., (2006) "I'm Not seen as One of the Clever Children': Consulting Primary School Pupils about the Social Conditions of Learning", Educational Review, 58 pp.171-181

[35] Roberts-Holmes, G. (2014) The 'datafication' of early years pedagogy: 'if the teaching is good, the data should be good and if there's bad teaching, there is bad data'. Journal of Education Policy, DOI: $10.1080 / 02680939.2014 .924561$.

[36] Rudduck, J. \& J. Flutter, (2004) How to Improve Your School: Giving Pupils a

Voice. New York and London: Continuum.

[37] Sammons, P. \& R. Smees, (1998) 'Measuring Pupil Progress at Key Stage 1: Using Baseline Assessment to Investigate Value Added', School Leadership \& Management, 18 (3) pp.389 - 407

[38] Schagen, I., M. Sainsbury \& S. Strand, (1999). 'Statistical aspects of baseline assessment and its relationship to end of key stage one assessment'. Oxford Review of Education, 25(3), 359-367

[39] Strand, S., (1997) 'Pupil Progress during Key Stage 1: A Value-Added Analysis of School Effects', British Educational Research Journal, 23 (4) pp.471 - 487

[40] Strathern, M., (2000) 'The Tyranny of Transparency', 26 pp.309-321

[41] Sylva, K., E. Melhuish, P. Sammons, I. SirajBlatchford \& B. Taggart, (2004) The Effective Provision of Pre-School Education (EPPE) Project: Findings from PreSchool to End of Key Stage 1, London: Sure Start.

[42] TACTYC (2014) Position statement. Say 'no' to Baseline Assessment. http://tactyc.org.uk/wpcontent/uploads/2014/10/TACTYC-Baseline-positionpaper.pdf.

[43] Tickell, C., (2011) The Early Years: Foundations for Life, Health and Learning: An Independent Report on the Early Years Foundation Stage to Her Majesty's Government, London: Department for Education.

[44] Troman, G., (2008) 'Primary Teacher Identity, Commitment and Career in Performative School Cultures', British Educational Research Journal, 34 pp.619-633

[45] Tymms, P., C. Merrell, D. Hawker \& F. Nicholson, (2014). Performance Indicators in Primary Schools: A comparison of performance on entry to school and the progress made in the first year in England and four other jurisdictions
Research Report. DFE-RR344: CEM Centre, Durham University 2014. 